\title{
Analysis of Culture Education in Teaching Chinese to Speakers of Other
}

\section{Languages}

\author{
Wang Cunbao \\ College of Humanities in Xi'an International University, Xi'an, Shaanxi, 710077 \\ 1252158573@qq.com
}

Key words: Teaching Chinese to Speakers of Other Languages, culture education, analysis

\begin{abstract}
Advanced Placement Program (AP) is a symbol of Chinese education in America. It reflects the concept of teaching Chinese in America, which means it puts emphasis on the importance of culture education. Culture education is closely related with language teaching, and so is the Chinese and Chinese culture in particular. People usually acquire not only Chinese language itself, but more importantly they acquire the Chinese culture deeply rooted in the language. So on the basis of analyzing the current situation of culture education in teaching Chinese to speakers of other languages, this paper aims to explore the mode of culture education in teaching Chinese to speakers of other languages, then finally puts forward some constructive suggestions.
\end{abstract}

\section{Introduction}

Since 21st century, China boosts its economy at an alarming speed and it has become the world's second largest economy which enjoys great popularity globally. With its strong capability and rising international status, developing the soft power has become an important task. In order to make China more popular, Chinese language and culture is an inevitable way to get foreigners acknowledge China. Teaching Chinese to speakers of other languages has moved to a new stage since the opening of the First World Chinese Conference in 2005. Therefore, more and more people begin to chase "the craze of learning Chinese". Language and culture are supplementary to each other. When learning Chinese, we are learning the unique Chinese culture as well. So on the basis of analyzing the current situation of culture education in teaching Chinese to speakers of other languages, this paper aims to explore the mode of culture education in teaching Chinese to speakers of other languages, then finally puts forward some constructive suggestions.

\section{Culture Education and Teaching Chinese to Speakers of Other Languages}

Teaching Chinese to speakers of other languages has gained more popularity and been attached greater importance by the international community. Since the Advanced Placement Program started in American senior high schools in 2006, teaching Chinese to speakers of other languages has become more and more popular. Started by the US government, AP is a preliminary program open to senior high school students so that they can easily and conveniently apply for famous universities. Among the 33 subjects in AP, Chinese and Chinese culture program is a newly emerged one. In recent years, such countries as US, UK, South Korea and Thailand introduce Chinese and Chinese culture into their preliminary and senior high school system as optional course or required course, which reflects that the internalization of Chinese has become more and more obvious. What is known to us is Confucius Institute in America. A large number of Chinese teachers who have a 
good command of English set their feet on other countries to teach Chinese and Chinese culture, which exactly reflects the internalization of Chinese education. Culture is the vehicle of language. With culture, language is nothing.

Teaching Chinese to speakers of other languages essentially is a kind of second language teaching. It is an applied subject which cultivates learners' language proficiency. More importantly, it cultivate learners' cross-cultural communicative competence. With this aim, it will be easier to understand the content and object of culture education in teaching Chinese to speakers of other languages. Compared with language teaching, culture teaching covers a much wider area. however, culture teaching in international Chinese education should be in consistent with its nature and purpose. That means the content of culture education is closely related to communication area of language learners so as to cultivate their language competence, communicative competence and cross-cultural competence. Culture education serves an important aid for learners to settle culture barriers, then they will have a better understanding and acknowledgement of the target language country.

The current culture education in teaching Chinese to speakers of other languages is diversified. Some of them are more systematical, while others are more casual. On the whole, culture education mainly consists of culture teaching in textbook explanation of classroom teaching, or culture knowledge embodied in textbooks for learners to acquire. Obviously, still some of them may adopt teaching methods like different textbooks about culture education in different periods. Firstly, in this global age, more and more people start to learn Chinese and those who learn Chinese are from various countries, which makes it complicated. Such as Chinese learners from South-east Asian countries, including Japan, South Korea, Malaysia and Thailand. They are deeply influenced by Confucius culture and there are few differences between them. So as for them, leaning Chinese is much easier. However, learners from Europe, US, Africa and Middle-East countries have different cultural background with Chinese people. So it's much more difficult for them to learn Chinese. To conclude, as for culture education, cultural background of those learners plays an important role. So far, there are no clear categories for learners from different countries based on different cultural backgrounds when learning Chinese. So, there exists a problem that efficiency is not high and the effect is not obvious. Secondly, as for teachers of culture education, whatever they are with Chinese history background or with professional knowledge of teaching Chinese to speakers of other languages, they are not so qualified to spread culture in language teaching. Thirdly, the textbooks about culture teaching are various, and most of them are outdated and not so practical. All those are really the problems existing in culture education in teaching Chinese to speakers of other languages.

\section{Mode of Culture Education in Teaching Chinese to Speakers of Other Languages}

AP Chinese course not only stresses learning language itself but also put more emphasis on the fact that learners should have more access to the rich culture in learning languages. Essentially speaking, foreign language learning is not only confined to learning words, phrases, grammar, more importantly it involves understanding and mastering the culture meaning in the language context. Chinese learners should be very culturally sensitive so that they will have a clear aim of learning and understanding Chinese culture rather than language itself. AP Chinese culture course has a wider area of culture practice, culture product and culture concept, which consists of classic culture and literature and development of contemporary social civilization. It is very rich, timely and practical, which will help learners improve their language proficiency and finally help them have deeper understanding of Chinese history, culture and current situation. Through learning AP 
Chinese culture courses, learners not only learn important events, invention in history, but also every aspect of the development of contemporary society, especially the food and scenery spots. Therefore, learners can learn a real and dynamic China and its culture with this kind of culture education.

Modes and means of culture education in teaching Chinese to speakers of other languages is seeking improvement. When AP foreign language courses were started, language and culture were taken as two independent individuals to be taught. For example, Chinese course mainly involves teaching learners Chinese language. Chinese literature mainly involves teaching learners appreciate Chinese classic literary works. However, in the process of teaching, people find that combining culture with language as a subject, which is AP Chinese and culture course. By doing so, culture can be well penetrated into language teaching and learning. This is what we call as culture immersion. In classroom learning, learners can feel the culture atmosphere, such as the decoration of classrooms and class activities. By doing so, learners can have a real feeling. In the teaching process, learners have free interactive activities like demonstration, role plays and group activities to drive students acquire culture knowledge. After class, teachers can also organize and introduce some colorful cultural activities, such as Peking opera, movie dubbing, practice of Chinese martial art and Tai Ji, and other forms of folk art and instruments. All of these belong to culture learning and learners can unconsciously acquire Chinese culture.

Teachers of teaching Chinese to speakers of other languages shoulder the responsibility of spreading international Chinese culture and teaching cross-cultural competence. They should not only be good at Chinese language and Chinese culture but also have certain understanding of those learners' native culture. Besides, they should realize the importance and clear aim of their job. Therefore, not only should teachers have a good command of professional knowledge, strong language competence, ability of analyzing and summarizing and the ability to deal with some practical problems, but also have the related cross-cultural language teaching, which means teachers should know learners' native language and the culture background of the second foreign language. It can be demonstrated in the following aspects. Firstly, teachers should have a full and all-round knowledge structure. Secondly, teachers should be very clear about their own roles-the role of educators. Thirdly, teachers should know clearly about Chinese culture because their first task is to spread knowledge and culture is the key to knowledge. Last but not the least, teachers should have a certain cross-cultural communicative competence. In the process of teaching Chinese to speakers of other languages, communication is the key. Teachers should teach students how to communicate with Chinese and help them know more about Chinese culture.

Textbooks serve as an aid to teaching. They are the important tool for learners to learn Chinese culture and language, learn common sense of cross-culture. In class, textbooks are materials for teachers to help learners get to know exactly the knowledge system, the key and difficult points. What's more, textbooks can offer the real scene for students to experience the real colorful activities designed by teachers so that students' activeness in leaning will be stimulated. Therefore, when composing or selecting textbooks, authors or teachers should be very clear about the subject who use the textbooks so that according to different subjects and their language and cultural background, teachers should teach selectively.

In the teaching Chinese to speakers of other languages, the design of teaching environment plays an important role. Teachers can design different culture context based on traditional Chinese cultural festivals, then introduce different customs to students. Besides, teacher can also create more activities related to Chinese culture, such as traditional Chinese Spring Festival or Mid-autumn Day. 
By doing so, students can feel and learn Chinese culture in a real scene to ensure that they have a better understanding of Chinese culture.

In the process of culture education in teaching Chinese to speakers of other languages, teachers can adopt different strategies. Firstly, comparison is one of the strategies commonly used in AP Chinese culture teaching. It refers to allowing students to know the native culture and the culture of target language, then make a comparative analysis to get the differences so that teachers can be clear about their teaching goal. Secondly, experimental teaching is a strategy considering the needs of teaching itself in which teachers will do their best to involve students and put them in the environment designed exclusively for students to get to know what they taught. This strategy is students-centered, and teachers only need to lead rather than teach. Thirdly, task-based teaching stresses learning in the practice, which enables students to learn actively, inspires students to participate in activities so as to achieve effective teaching. Last but not the least, theme activity teaching is the most effective one. China has five thousand years of culture and profound history, so teachers can design different lectures and discussion activities on theme culture. what's more, teachers can also make full use of the full tourism resources and sceneries to organize students to participate in some cultural activities. In addition, teachers can start some research activities on environmental protection, love and marriage concept, etc. which all contributes to the culture education in teaching Chinese to speakers of other languages.

\section{Conclusion}

Culture education plays an important role in teaching Chinese to speakers of other languages. With the global popularity of teaching Chinese to speakers of other languages, American in particular, more and more people have realized the importance of culture education. Therefore, this paper has analyzed culture education in teaching Chinese to speakers of other languages from many aspects so as to put forward some constructive and valuable suggestions for teachers, textbooks, teaching environment and teaching strategies.

\section{References}

[1] Du Daoming. An Introduction of Chinese Culture as the Second Language Teaching [M]. Press of Peking University, 2008

[2] Hu Mingyang. Cultural Element in Teaching Chinese to Speakers of Other Langauges[J]. Language Teaching and Research, 1993(04)

[3] Ju Feng. Developmental Base of Teaching Chinese to Speakers of Other Languages[J]. Chinese Journal of Social Science, 2011(01)

[4] Cen Yingying. Comparative Study of Culture Project in Chinese Textbooks[M]. Ji Nan University, 2012 